\title{
Variation of Alkali Concentration and Temperature: Its Effect on the Morphology of ZnO Nanoparticles Synthesized via Solvothermal Technique
}

\author{
B.S. Wee ${ }^{1, a^{*}}$, E.K. Droepenu ${ }^{2, b^{*}}$, S.F. Chin ${ }^{3, c}$, K.Y. Kok ${ }^{4, d}$, W. Ting ${ }^{5, e}$. \\ ${ }^{1,2,3,5}$ Resource Chemistry Program, Faculty of Resource Science and Technology, \\ Universiti Malaysia Sarawak 94300, Kota Samarahan, Sarawak, Malaysia.
}

${ }^{2}$ Graduate School of Nuclear and Allied Sciences, University of Ghana, AE1, Kwabenya-Accra, Ghana.

${ }^{4}$ Malaysian Nuclear Agency, Bangi, Kajang, 43000 Selangor, Malaysia.

a*swboon@unimas.my; bkobladodzie01@yahoo.com, 'sfchin@unimas.my, dkykok2020@gmail.com, 'wting@unimas.my

Keywords: Solvothermal technique, Spectroscopy, Nanostructures, Nucleation time, Zinc oxide.

\begin{abstract}
This study reports on synthesis of $\mathrm{ZnO}$ nanostructures using Zinc chloride $\left(\mathrm{ZnCl}_{2}\right)$ as precursors and Potassium hydroxide $(\mathrm{KOH})$ as alkaline source in a solvothermal process with varying molar concentrations $\left(\mathrm{Zn}^{2+} / \mathrm{OH}^{-}\right)$of $1: 1,1: 3$ and $1: 5$ for temperatures of $30^{\circ} \mathrm{C}$ and $50{ }^{\circ} \mathrm{C}$. The synthesized nanostructures were characterized by X-Ray Diffraction (XRD), Field Emission Scanning Electron Microscopy (FE-SEM), Transmission Electron Microscopy (TEM), Fourier Transform Infrared (FT-IR) Spectroscopy, and Ultraviolet Visible (UV-Vis) spectroscopy. ZnO nanostructures synthesized at lower ratios (1:1) exhibited wurtzite hexagonal shapes. However, as the concentration ratios increases in both cases, spherical structures were formed with the emergence of some rod-like structures dominating, and finally aggregated to form flower-like structures at $30{ }^{\circ} \mathrm{C}$ temperature. The average crystallite size for nanostructures from XRD $\left(30-50{ }^{\circ} \mathrm{C}\right)$ were in the range $15-21 \mathrm{~nm}$ whereas the average particle size from TEM analysis $\left(30-50{ }^{\circ} \mathrm{C}\right)$ were in the range 39-76 $\mathrm{nm}$. Increase in temperature and molar concentration of the alkaline source generally decreased the crystallite and particle size of the as well as a decrease in the wavelength of $\mathrm{ZnO}$ nanostructures as a result of blue-shifting of the absorption peak. FT-IR spectra of $\mathrm{ZnO}$ NSs prepared from concentration ratios of $\mathrm{Zn}^{2+}: \mathrm{OH}^{-}(1: 1,1: 3$ and $1: 5)$ at $30^{\circ} \mathrm{C}$ and $50{ }^{\circ} \mathrm{C}$ showed characteristic peak bands at $461-467 \mathrm{~cm}^{-1}$ and $460-462 \mathrm{~cm}^{-1}$ respectively.
\end{abstract}

\section{Introduction}

Zinc oxide $(\mathrm{ZnO})$ is a useful material with diverse and remarkable properties including its high photosensitivity, redox potential, non-toxic, and chemical/thermal/mechanical stability [1]. Due to this remarkable properties, they are useful in electronics, optics and photonics because of their relatively wide band gap of $3.4 \mathrm{eV}$. Sensors, transducers, catalyst, light emitting diodes, drug delivery, are some other applications of Zinc oxide [2,3,4,5,6,7]. The numerous applications of $\mathrm{ZnO}$ demands an in-depth knowledge in their growth mechanisms to achieve the specified morphological structures. Some of these structures include nanocombs, nanorings, nanohelixes, nanobelts, nanowires, nanocages. However, different parameters must be taken into consideration to achieve these structures. Some of which include $\mathrm{pH}$, precursor type and its concentration, reaction/growth time, and calcination temperature. These parameters can be employed in different synthesizing techniques to achieve the desired nanostructure. Some of these techniques are precipitation and co-precipitation [8, 9, 10], sol-gel [11], wet chemical process [12], Electrochemical Deposition Techniques [13], solochemical processing [14], Sputter Deposition Techniques [15], hydrothermal process [16], Pulse Laser Deposition [17] and Chemical Vapor Deposition [18]. All these techniques are made up of complex processes with very high energy demand. 